\title{
Correction to: Machine Learning for Identifying Emotional Expression in Text: Improving the Accuracy of Established Methods
}

\author{
Erin Bantum ${ }^{1}$ • Noémie Elhadad ${ }^{2}$. Jason E. Owen ${ }^{3}$. Shaodian Zhang ${ }^{2} \cdot$ Mitch Golant $^{4}$ • Joanne Buzaglo ${ }^{4}$. \\ Joanne Stephen ${ }^{5} \cdot$ Janine Giese-Davis ${ }^{6}$
}

Published online: 22 September 2020

(C) Springer Nature Switzerland AG 2020

\section{Correction to: Journal of Technology in Behavioral}

Science

$$
\text { https://doi.org/10.1007/s41347-017-0015-5 }
$$

The original version of this article unfortunately contained a mistake. The name of "Erin Bantum" is now corrected in the author group.

Publisher's Note Springer Nature remains neutral with regard to jurisdictional claims in published maps and institutional affiliations.

The online version of the original article can be found at https://doi.org/ 10.1007/s41347-017-0015-5

Erin Bantum

ebantum@cc.hawaii.edu

1 Cancer Prevention \& Control Program, University of Hawaii Cancer Center, Honolulu, HI, USA

2 Biomedical Informatics, Columbia University, New York, NY, USA

3 Dissemination \& Training Division, VA Palo Alto Health Care System, Livermore, CA, USA

4 Cancer Support Community, Washington, DC, USA

5 Alberta Health Services, Calgary, Alberta, Canada

6 Cumming School of Medicine, Department of Oncology, University of Calgary, Calgary, Alberta, Canada 